\title{
Charphy Impact of Medium Molecular Weight Phenol Formaldehyde (MMwPF) Plywood
}

\author{
Hasmawi Khalid ${ }^{1, *}$, Norhayati Ibrahim² \\ 1 Jabatan Kejuruteraan Awam, Politeknik Sultan Salahuddin Abdul Aziz Shah, Persiaran Usahawan, Seksyen U1, 40150 Shah Alam, Selangor, \\ Malaysia \\ 2 Jabatan Kejuruteraan Mekanikal, Politeknik Sultan Salahuddin Abdul Aziz Shah, Persiaran Usahawan, Seksyen U1, 40150 Shah Alam, Selangor, \\ Malaysia
}

\section{ABSTRACT}

Plywood is a wood product frequently utilized in building as part of concrete formwork systems. In the concreting process, plywood formwork needs to be strongly made to withstand the pressure subjected by the wet concrete as well as the impact. To reduce the dependency on solid timber as plywood, oil palm stem offers alternative materials. There are four main weaknesses of oil palm stem (OPS) as a material for plywood manufacturing; high variations in density and moisture content (MC), high water absorption and high surface roughness. Therefore, this study modified the drying and treatment process of OPS veneer. The veneer was predried by using roller presser for removing a large amount of water and later treated with medium molecular weight phenolformaldehyde (MMwPF) to bond together parenchyma tissue, cell wall, and a lumen for much uniform density and better surface bonding. The Charpy impact of OPS plywood developed in this study denoted as PTA was investigated. These properties were compared with the properties of another two types of commercial OPS plywood denoted as PTB and PTC which were manufactured using OPS veneer with tropical hardwood veneer for face and back veneer and control plywood denoted as PTD which was manufactured using $100 \%$ tropical hardwood veneer. The results showed that PTA has the highest mean value of energy and strength for both notched and unnotched Charpy impact.

\section{Keywords:}

Oil palm stems plywood; medium molecular weight phenol formaldehyde;

\section{Introduction}

Plywood has been used by millennia in construction industry and one of the major contributors to Malaysian economy. The plywood industry from tropical wood species constituted $21 \%$ of the total timber exported products in 2015 and this is expected to increase annually [1]. Although the demand of plywood is increased, it also suffers due to the shrinkage of wood sources and consequently increment of logs price [2]. The logs production volume decreased to 4.4 million $\mathrm{m}^{3}$ from 6.5 million $\mathrm{m}^{3}$ in year of 2005 . This was due to the heavy logging activity which damaged the potential tree for

\footnotetext{
* Corresponding author.

E-mail address: hasmawi@psa.edu.my

https://doi.org/10.37934/araset.18.1.2430
} 
future source. In order to support wood-based panel industry, the use of wood and non-wood residue as a source is an ideal way to overcome this issue.

Oil palm (Elaeisguineensis Jacq) is a non-wood material and are the most abundant crops planted which can be obtained at any plantation around Malaysia. Based from statistical data of Malaysian Palm Oil Board, there are 5.39 million ha of land are being planted with this agriculture in 2014 [3], [4]. The oil palm stems (OPS), oil palm fronds (OPF) and oil palm empty fruit bunches (EFB) is the residues that are left behind after cutting process as the tree reach 25 to 30 years age [5]. Among oil palm residues, OPS is the biggest residue with a total of 13.6 million can be obtained from $100000 \mathrm{~h}$ of replanting each year. The abundant of OPS after falling not only increase the liability of the industry due to the difficulty to be dispose, but also lowering the quality of seedlings due to the attack of the biodeteriorating agent. The uses of oil palm residue as raw material in wood- based panel reduce on the costs of production and increase on economic growth of the country. According to Paridah and Anis [6], the oil palm stem veneer could be used as an alternative raw material for LVL and plywood manufacture. However, the drawback of OPS veneer is its high moisture content and segregation in density.

Veneer drying to reduce moisture content after peeling is an important process in plywood manufacturing [7]. The temperature used to drying the veneer significantly affected on the mechanical and physical properties of plywood. The process took approximately $70 \%$ and $60 \%$ of production energy consumed and mill energy requirement [8]. Since moisture content of OPS could be as high as 500\% [9], high temperature is required in drying the veneer; this however increases the cost of plywood production.

Quite a number of researches have been conducted in improving the drying process of plywood veneers $[10,11]$ in order to enhance the properties of plywood. The moisture in the veneer can be removed by roller presser method. To further enhance the properties of the plywood, the veneer was impregnated with phenolic resin. Impregnated the veneer with low molecular weight phenolic resin has resulted in the properties of the OPS plywood which is still not as good as medium molecular weight phenolic resin.

Therefore in this study, the roller pressing method has been used for pre-dying prior to oven dry and at the same time the produced OPS veneer was impregnated with medium molecular weight phenolic resin with the aim to improve the physical and mechanical properties of plywood. The properties of this new process of OPS plywood were compared with commercial plywood.

\section{Methodology}

\subsection{Materials}

\subsubsection{Plywood}

Four sources of plywood were used in this study. PTA is the plywood prepared by the author using $100 \%$ oil palm plywood with the veneers treated with phenol formaldehyde. PTB and PTC were commercial oil palm plywood from two commercial factories. This plywood used tropical veneer for its face and back layer and PTD was tropical plywood.

\subsubsection{Manufacturing of $100 \%$ Oil Palm Plywood (PTA)}

Three fresh pieces of outer OPS veneers with thickness between 4.5-6.0mm were cut to the dimensions of $4 \times 3$ feet. The veneer was then feed into roller pressing machine with the gap of the roller; $R_{1}: R_{2}: R_{3}=3.5: 2.8: 2.8 \mathrm{~mm}$ and speed of the roller was $8.0 \mathrm{rpm}$ to squeeze out the water. Then, the veneer passing through a continuous roller dryer with temperature at $150^{\circ} \mathrm{C}$ and speed $480 \mathrm{rpm}$ 
for 1 hour until the final moisture content $(\mathrm{MC})$ of the veneers were 0\%MC. After that, Medium molecular weight phenol formaldehyde (MMwPF) with ratio 80:20 for resin and water respectively and solid content $49.1 \%$ was applied two times on the veneer through glue spreader in gluing process. Then these veneers undergoes plattern press machine for pre-curing process for 9 minutes with the temperature of the plate ranging between $90-140^{\circ} \mathrm{C}$. The targeted $\mathrm{MC}$ at this stage was between $6-20 \% \mathrm{MC}$. These veneers were combined together and subjected to heat and pressure in the hot press until the glue was cured to form plywood panels at a temperature $115^{\circ} \mathrm{C}$ and pressure $120 \mathrm{~kg} / \mathrm{cm}^{3}$ for 15 minutes. After curing the boards are ready to be used. Fig. 1 . shows the different types of plywood used in this study.

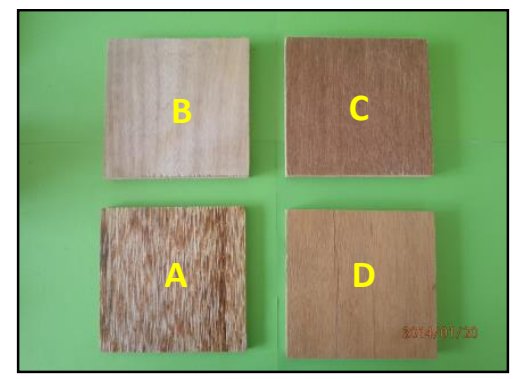

Fig. 1. Different types of plywood; A- PTA, B- PTB, C- PTC, D-PTD

\subsection{Methods}

The mechanical properties of the plywood were determined for charpy impact strength properties.

\subsubsection{Determination of Charpy Impact Strength}

A total of 80 charpy impact specimens were cut into rectangular strips with dimensions approximately of $125 \mathrm{~mm} \times 12.7 \mathrm{~mm} \times$ actual thickness $(\mathrm{T})$. The included angle of notch shall be $45 \pm 1^{\circ}$ with a radius of curvature at the apex of $0.25 \pm 0.05 \mathrm{~mm}$. The plane bisecting the notch angle shall be perpendicular to the face of the test specimen within $2^{\circ}$. The charpy impact tests were performed according to American Society for Testing and Materials ASTM D 6110 (ASTM, 2010) [12]. The set up was shown in Fig. 2.

The specimens shall be of nominal width only. Measure and record the width of each specimen after notching to the nearest $0.025 \mathrm{~mm}(0.001 \mathrm{in})$. The depth of each specimen under the notch was measure and record material to the nearest $0.025 \mathrm{~mm}(0.001 \mathrm{in})$. Position a test specimen horizontally on the supports and against the anvils so that it will be impacted on the face opposite the notch. Center the notch between the anvils. Raise and secure the pendulum in the release mechanism and reset the indicating mechanism. Release the pendulum, allowing the striking edge of the pendulum to impact the specimen. A specimen that does not break completely into two or more pieces is not considered to be broken. The data records in this study were used to calculate the net breaking energy and impact resistance using Equation 1 and Equation 2.

Net breaking energy $=$ Breaking energy $-($ windage + friction $)$ 
Impact resistance $=$ Net breaking energy $/$ measured width

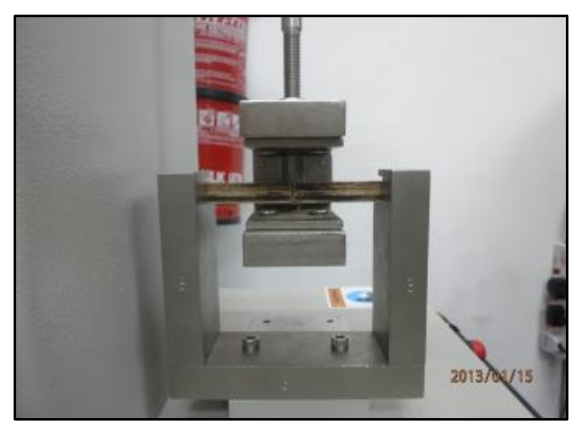

Fig. 2. Experimental Set-up for Charpy Impact Test

\section{Results}

The mechanical properties of plywood from four different sources were tested and evaluated.

\subsection{Charpy Impact}

Charpy impact test is a standard high strain-rate test which determines the amount of energy absorbed by a material during fracture while breaking under an impact load. The charpy impact test can be used as an economical quality control method to determine the notch sensitivity and impact toughness of materials. The notch serves as a stress concentration zone and some materials are more sensitive towards notches than others. Therefore this section reports the study on the impact strength for unnotched and notched plywood.

\subsection{Notched and Unnotched}

The results showed that the energy value of charpy notched and charpy unnotched were respectively in the range of $1.65(\mathrm{~J})$ and $2.27(\mathrm{~J})$ to $4.78(\mathrm{~J})$ and $5.71(\mathrm{~J})$ respectively while, strength value range from $129(\mathrm{~J} / \mathrm{m})$ and $163(\mathrm{~J} / \mathrm{m})$ to $377(\mathrm{~J} / \mathrm{m})$ and $449(\mathrm{~J} / \mathrm{m})$.

The highest energy (see Fig. 3. and Fig. 4.) and impact strength (see Fig. 5. and Fig. 6.) value was found in PTA (100\% OPS plywood) which was glued with phenolic resin and the lowest was PTB which was glued with urea formaldehyde resin. The energy and strength for the four types of plywood specimen was calculated using Equation 1 and Equation 2, respectively.

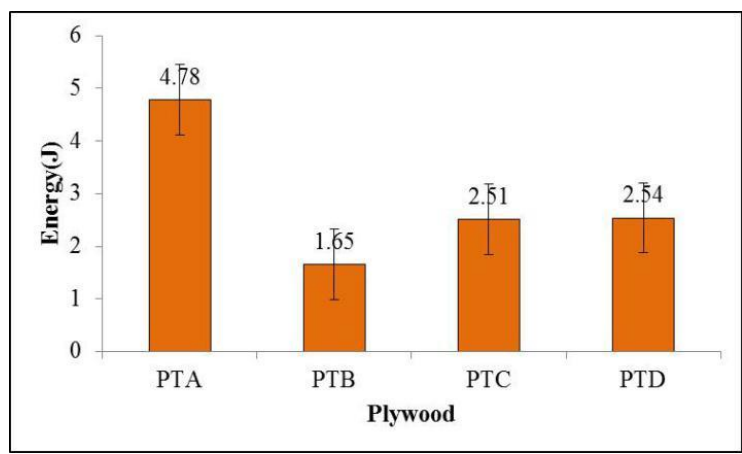

Fig. 3. Energy of OPS-Plywood (PTA) and Commercial-Plywood (PTB, PTC and PTD) in Charpy Impact Notched Sample 


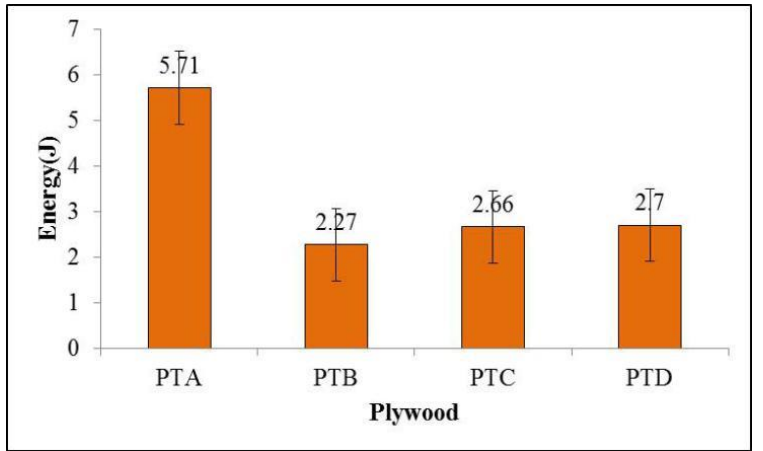

Fig. 4. Energy of OPS-Plywood (PTA) and Commercial-Plywood (PTB, PTC and PTD) in Charpy Impact Unnotched Sample

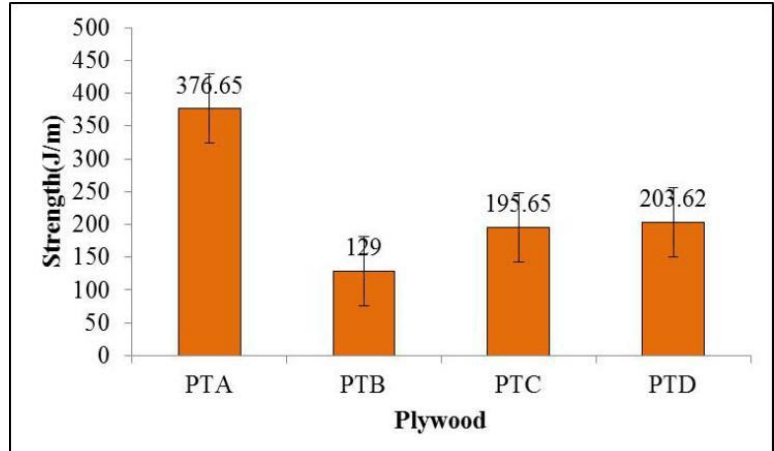

Fig. 5. Strength of OPS-Plywood (PTA) and Commercial-Plywood (PTB, PTC and PTD) in Charpy Impact Notched Sample

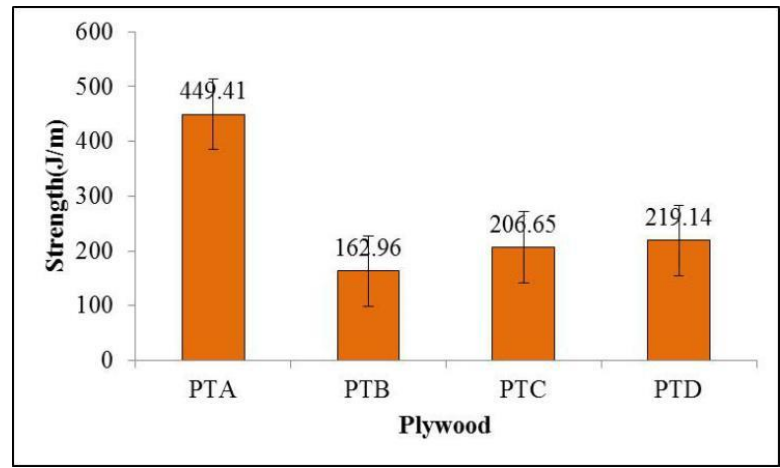

Fig. 6. Strength of OPS-Plywood (PTA) and Commercial-Plywood (PTB, PTC and PTD) in Charpy Impact Unotched Sample

It is interesting to note that there is no significantly difference between PTB, PTC and PTD except with PTA for energy and strength in both (charpy impact notched and charpy impact unnotched) tested. Higher energy required to buckle the wood structure due to the rigid structure of polymer in wood prove that the phenol formaldehyde has well penetrated thus enhanced the impact tested of plywood.

\subsection{Failure Characteristics of Charpy Impact}

The mode of failure of plywood loaded in charpy impact tests are classified in percentage as complete break, hinge break, partial break and non-break. Fig. 7. (a) and Fig. 7. (b) show the mode of failure for complete break where a break in which the specimen separates into two or more pieces after charpy impact notched and charpy impact unnotched tested, respectively. The hinge and partial 
break was also observed in Commercial-Plywood as shown in Fig. 7. (c) and Fig. 7. (e) and OPSPlywood as shown in Fig. 7. (d) and Fig. 7. (f) specimen where it show incomplete break such as that both part of the specimens are held together only by a thin peripheral layer in the form of a hinge having low residual stiffness and incomplete break that does not meet the definition for hinge break, respectively.

In charpy impact unnotched tested, it can be summarized that all of the plywoods (PTA, PTB, PTC and PTD) type had break, hinge break and partial break value approximately of $82.5 \%, 8.75 \%$ and $8.75 \%$ while for charpy impact notched tested, the break, hinge break, partial break contributes about $88.75 \%, 1.25 \%$ and $10.00 \%$, respectively of total specimen.

The results showed that PTA has the highest mean value of energy and strength for both notched and unnotched charpy impact.

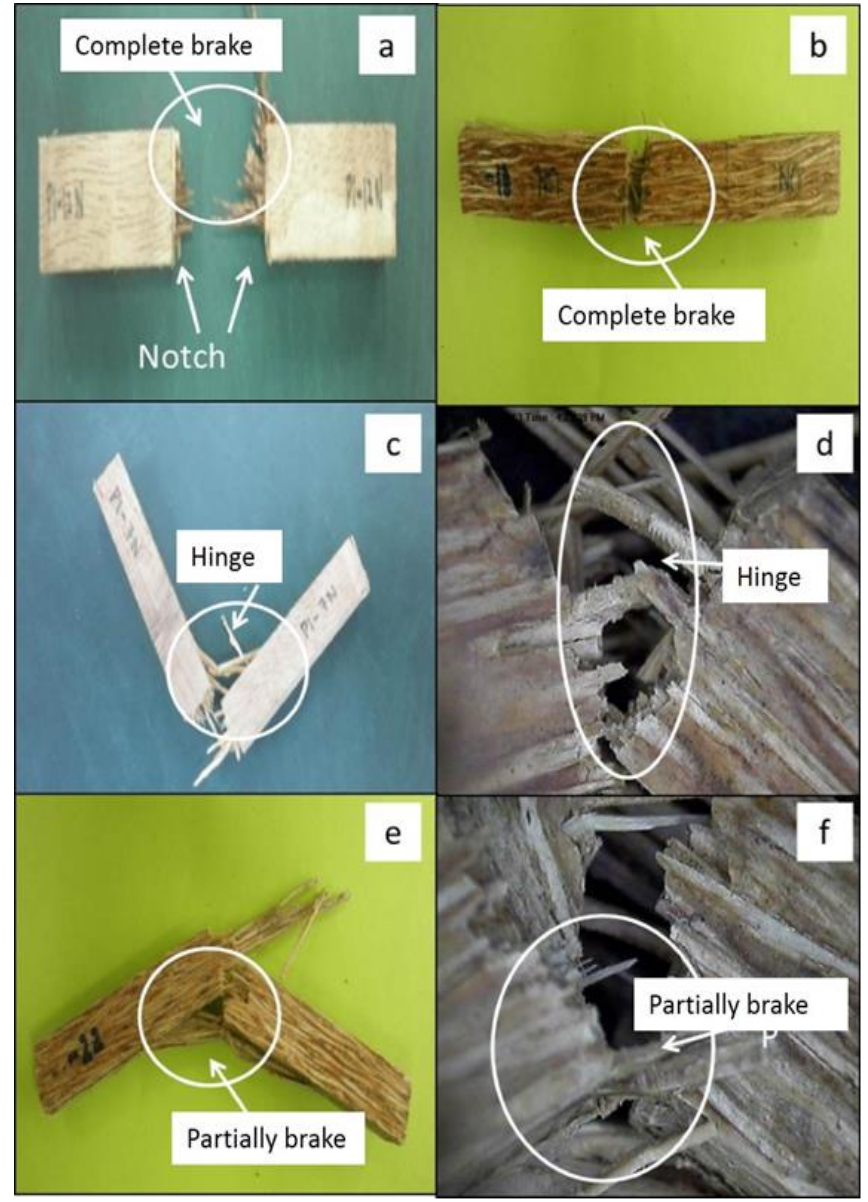

Fig. 7. (a) Failure Mode of Complete Break in Charpy Impact Notched (b) Complete Break in and Charpy Impact Unnotched, (c) Hinge Break, (d) Hinge Break under Microscopy View, (e) Partial Break and (f) Partial Break under Microscopy View

\section{Acknowledgement}

The authors would like to express greatest appreciation and gratitude to the Universiti Teknologi MARA of Malaysia (UiTM), Universiti Putra of Malaysia (UPM) and Malaysian Timber Industrial Boards (MTIB) for assisting and funding this study. Thanks are also rendered to Plus Intervest Sdn. Bhd and 
Central Kedah Plywood Industry Sdn. Bhd. for supplying OPS Plywood and processing facalities and Malayan Adhesive and Chemicals (M) Sdn. Bhd. for providing the MMwPF resins.

\section{References}

[1] MTIB-Statistic-Malaysian

major export

http://www.mtib.gov.my/index.php?option=com_content\&view=article\&id=2034\%3Amalaysia-majorexport\&catid=44\%3Astatistic\&lang=en (accessed on $17 \mathrm{Feb} 2016$ ).

[2] Rahim, AS Abdul, and HO Mohd Shahwahid. "Short-and long-run effects of sustainable forest management practices on West Malaysian log supply: an ARDL approach." Journal of tropical forest science (2009): 369-376.

[3] Baharuddin, Azhari Samsu, M. Wakisaka, Y. Shirai, Suraini Abd-Aziz, Rahman Abdul, and M. A. Hassan. "Cocomposting of empty fruit bunches and partially treated palm oil mill effluents in pilot scale." International Journal of Agricultural Research 4, no. 2 (2009): 69-78.

https://doi.org/10.3923/ijar.2009.69.78

[4] MPOB-Malaysian oil palm statistics (2014) http://bepi.mpob.gov.my/images/area/2014/Area summary.pdf (accessed on 10 September 2014)

[5] Mokhtar, Anis, Kamarudin Hassan, Astimar Abdul Aziz, and MohdBasri Wahid. "Plywood from oil palm trunks." Journal of Oil Palm Research 23 (2011): 1159-1165.

[6] Paridah, M. T., and M. Anis. "Process optimization in the manufacturing of plywood from oil palm trunk." In Proc. 7 th National Seminar on the Utilization of Oil Palm Tree, pp. 12-24. 2008.

[7] Walker, John CF. Primary wood processing: principles and practice. Springer Science \& Business Media, 2006.

[8] Ozsahin, Sukru, and Ismail Aydin. "Prediction of the optimum veneer drying temperature for good bonding in plywood manufacturing by means of artificial neural network." Wood science and technology 48, no. 1 (2014): 5970 .

https://doi.org/10.1007/s00226-013-0583-2

[9] Bakar, Edi Suhaimi, Mohd Hamami Sahri, and P. S. H'ng. "Anatomical characteristics and utilization of oil palm wood." The formation of wood in tropical forest trees-a challenge from the perspective of functional wood anatomy (2008): 161-178.

[10] Loh, Yueh Feng, Tahir Md Paridah, Yeoh Beng Hoong, Edi Suhaimi Bakar, Mokhtar Anis, and Husain Hamdan. "Resistance of phenolic-treated oil palm stem plywood against subterranean termites and white rot decay." International Biodeterioration \& Biodegradation 65, no. 1 (2011): 14-17. https://doi.org/10.1016/j.ibiod.2010.05.011

[11] Choo, Adrian Cheng Yong, Paridah Md Tahir, Alinaghi Karimi, Edi Suhaimi Bakar, Khalina Abdan, Azmi Ibrahim, and Loh Yueh Feng. "Density and humidity gradients in veneers of oil palm stems." European Journal of Wood and Wood Products 69, no. 3 (2011): 501-503.

https://doi.org/10.1007/s00107-010-0483-1

[12] ASTM Standard D 6110-97. "Standard test methods for determining the Charpy impact resistance of notched specimens of plastics." Annual Book of ASTM Standards 8 (2002).

[13] Luckring, James M. "Initial experiments and analysis of blunt-edge vortex flows for VFE-2 configurations at NASA Langley, USA." Aerospace Science and Technology 24, no. 1 (2013): 10-21.

https://doi.org/10.1016/i.ast.2012.02.005 